\title{
Super - Fluorescence Quenching of 1-(E)-styryl-2- (4-(2-(E) - styrylphenoxy) Butoxy)Benzene (Alkoxy Bridged Styryl Benzene)(PPPBB) Colloidal Silver and Gold Nanoparticles
}

\section{Rasha M. Bayoumy}

Tanta University Faculty of Science

Shakir T. Abdel-Halim

Tanta University Faculty of Science

\section{Samy A. El-Daly}

Tanta University Faculty of Science

Ahmed A. Abo-Alhasan

Tanta University Faculty of Science

El-Zeiny M. Ebeid ( $\nabla$ elzeiny.ebeid@science.tanta.edu.eg )

Tanta University Faculty of Science https://orcid.org/0000-0002-5830-6470

\section{Research Article}

Keywords: 1-(E)-styryl-2-(4-(2-(E)-styrylphenoxy)butoxy)benzene, alkoxy bridged styryl benzene, Fluorescence quenching, Non-linear Stern Volmer plots, Metallic nanoparticles, Superquenching.

Posted Date: February 18th, 2022

DOI: https://doi.org/10.21203/rs.3.rs-1351595/v1

License: (c) (1) This work is licensed under a Creative Commons Attribution 4.0 International License.

Read Full License 


\section{Abstract}

The Super-efficient fluorescence quenching of the dye, 1-(E)-styryl-2-(4-(2-(E)-styrylphenoxy) butoxy) benzene (alkoxy bridged styryl benzene) (PPPBB), by silver and gold nanoparticles (Ag NPs and Au NPs) are explored by the steady-state fluorescence measurements in methanol and ethylene glycol $(\mathrm{MeOH}$ and EG). The data showed that both radiative and non-radiative energy-transfer perform a key role in the fluorescence super-quenching mechanism. The Stern-Volmer quenching constants $\left(\mathrm{K}_{\mathrm{sv}}\right)$ were calculated as $1.4 \times 10^{10}, 1.2 \times 10^{10} \mathrm{M}^{-1}$ in $\mathrm{MeOH}$ and EG for Ag NPs, and $2.69 \times 10^{8}, 6.18 \times 10^{9} \mathrm{M}^{-1}$ in $\mathrm{MeOH}$ and EG for Au NPs, respectively. Besides, the quenching sphere radius ( $r$ ) values were calculated, via Perrin model of quenching, as 160,161 nm in MeOH and EG for Ag NPs, and 45, $85 \mathrm{~nm}$ in MeOH and EG for Au NPs, respectively. From active sphere radius results, one can conclude that the fluorescence resonance energy-transfer is responsible for super-quenching of PPPBB. Moreover, the fluorescence energy-transfer had an observable effect on the fluorescence super-quenching of PPPBB by AgNPs and AuNPs in EG more than in $\mathrm{MeOH}$. These Super-quenching processes can pave the way for the usage of (PPPBB/ NPs) quenching systems in the energy transfer-based biosensors and essays with high degree of sensitivity.

\section{1- Introduction}

New methods for investigating the interaction between metallic nanoparticles and excited fluorophore were discovered through the rapid development of nanotechnology science over the last decades. The interactions between the metallic nanoparticles with fluorophores had a growing interest in recent years $[1,2]$. The near field interactions between fluorophores and metallic nanoparticles help in modification of the fluorescence emission [3, 4]. Dye emission depends on the shape, type, and size of metallic nanoparticles in the molecular probing / sensor's devices [5-7]. Many fluorophores acquire enhancement of fluorescence efficiency because of electronic coupling between the electronic transition dipole moment with surface plasmon. The dynamic quenching occurs from the quenching of organic molecules by nanomaterials [8-12]. Other research includes both static and dynamic quenching [13-18] in superfluorescence quenching processes. Nanoparticles induced superquenching find applications in biosensing, optical materials and scanning probe microscope [19].

Stilbene derivatives have several photophysical properties, so they are important in photo redox process which are used in solar energy conversion, biosensors, chemical sensors, dye laser, industrial dyes, phosphor scintillator and optical brighteners. Stilbene derivatives are chemically and thermally stable compounds and are not favorable starting materials for stilbene derivatives synthesis process due to the phenyl moieties stability. The hydroxylated derivatives (stilbenoids) are used as antibiotics (phytoalexins). Triazine stilbene derivatives are used in the paper industry and textile. They have an important role in the photochemical and biomedical investigations. Styryl benzene derivatives find application in biphotonic process, optics, colorant dyes, and laser dye [20-22]. The combination of amino stilbenes with the silver nanoparticles (AgNPs) produces a new photonic material [23]. Recently, natural compounds having a stilbene unit are characterized by anticancer activity [24]. Up-to date, the dye 1-(E)- 
styryl-2(4-(2-(E)-styryl phenoxy) butoxy benzene PPPBB has not yet been examined regarding quenching by nanometallic particles which is expected to have significant applications in biosensors and fluorescence-based assays. Herein, we reported the super-quenching processes of the PPPBB molecule by $\mathrm{Ag}$ and $\mathrm{Au}$ Nps to explore it's photophyscial interaction parameters and to pave the way for their usage as a sensitive systems for fluorescence-based biosensors.

\section{2- Experimental}

\subsection{Materials and chemicals}

All solvents and chemicals were acquired from Sigma Aldrich and were spectroscopic grade and used without further purification. $\mathrm{AgNO}_{3}$, tera chloroauric acid trihydrate $\left(\mathrm{HAuCl}_{4} \cdot 3 \mathrm{H}_{2} \mathrm{O}\right)$, and the reducing agent tri-sodium citrate were used to synthesize the Ag or gold nanoparticles AgNPs and (AuNPs) in doubly distilled water.

1-(E)-styryl-2-(4-(2-(E)-styrylphenoxy)butoxy)benzene (PPPBB) (Fig. 1) was kindly supplied from Prof. K. Müllen, University of Mainz, Germany. The method of PPPBB synthesis is described in previous work [25].

\subsection{Instrumentations :}

The electronic absorption spectra were recorded utilizing the Shimadzu UV-3101 PC spectrophotometer. emission and excitation spectra were recorded using a Jasco FP-8200 Spectrofluorometer, excitation bandwidth $5 \mathrm{~nm}$, emission band width $5 \mathrm{~nm}$, with Xe lamp light source. Fluorescence intensities were measured at right angle to the exciting light. Narrow entrances were used in order to minimize the intensity of the exciting light and thus to keep the photochemical reactivity (photoisomerization) at very low rate. The fluorescence decay was recorded by fluorescence lifetime measuring system Horiba fluoroCub3000U-EYM1.TEM measurements of silver and gold nanoparticles were measured using JEM100SX Model Electron microscope.

\subsection{Synthesis and characterization of silver nanoparticles:}

Silver nanoparticles were prepared by the well- known chemical reduction method [26,27]. In a typical procedure, $125 \mathrm{ml}$ of $1 \times 10^{-3} \mathrm{M}$ silver nitrate solution was heated to boiling and $5 \mathrm{ml}$ of $1 \%$ trisodium citrate solution (as nucleating and reducing agent) was added quickly. This resulted in a color change from pale yellow to golden yellow indicating the formation of AgNPs. Stirring was continued until cooled to room temperature. The nanoparticles were characterized by Transmission Electron Microscope (TEM) and UV-Vis absorption spectrophotometry. A typical solution of $51 \mathrm{~nm}$ diameter AgNPs having polygonal shape, exhibiting a characteristic surface plasmon band around $428.5 \mathrm{~nm}$ was obtained. TEM image of AgNPs with absorption spectrum are shown as an inset in Fig. (2).

\subsection{Synthesis and characterization of AuNPs:}


About $16.8 \mathrm{~nm}$ diameter AuNPs were prepared by the citrate reduction of $\mathrm{HAuCl}_{4} \cdot 3 \mathrm{H}_{2} \mathrm{O}$ [28-31]. An aqueous solution of $\mathrm{HAuCl}_{4} \cdot 3 \mathrm{H}_{2} \mathrm{O}(1 \mathrm{mM}, 100 \mathrm{~mL})$ was brought to a reflux while blending, and afterward $10 \mathrm{~mL}$ of a $1 \%$ trisodium citrate solution (as nucleating and reducing agent) was added rapidly, which brought out a change in solution color from pale yellow to deep red. After the color change, the solution was refluxed for an additional $15 \mathrm{~min}$, allowed to cool to room temperature. A typical solution of about $16.8 \mathrm{~nm}$ diameter gold particles exhibited a characteristic surface Plasmon band around $522 \mathrm{~nm}$. The size and mono disparity of the resulting nanoparticles was well documented for this method of synthesis [26]. The mechanism of the successive reduction of $\left[\mathrm{AuCl}_{4}\right]^{-}$ions into metallic AuNPs is explained in details in literature [32-34]. From the electronic absorption spectra of the prepared $16.8 \mathrm{~nm}$ diameter of $2.01 \mathrm{nM}$ concentration and 0.792 optical density (OD) at $\lambda_{\max }=522 \mathrm{~nm}$, one can calculate the extinction coefficient $(\boldsymbol{\varepsilon}(\lambda))$ of the prepared AuNPs. TEM image of AuNPs with absorption spectrum shown as an inset is shown in Fig. (2).

The molar absorptivity and concentration of $\mathrm{Ag}$ and Au nanoparticles were calculated according to reference [35]. Figure 2 ( $a$ and $b$ ) displays the TEM image of the set AgNPs and confirms the nano-scale dimensions of the particles of an average diameter of about $51 \mathrm{~nm}$. The electronic absorption spectrum of $2.5 \times 10^{-9} \mathrm{M}$ AgNPs aqueous solution presented a surface plasmon resonance peak at $420 \mathrm{~nm}$. Additionally, Fig. 2 (c and d) shows the TEM image of the prepared AuNPs confirming the nano-scale dimension of the particles of an average diameter of about $16.8 \mathrm{~nm}$. The electronic absorption spectrum of $6.9 \times 10^{-9} \mathrm{M}$ AuNPs aqueous solution presented a surface plasmon resonance peak at $520 \mathrm{~nm}$

\section{3- Results And Discussion}

Interaction of metallic nanoparticles with fluorophores is considered an active area of research [36-40]. To probe the microenvironment of the fluorophore, the fluorescence is quenched or enhanced in the proximity of the metallic nanoparticles depending on the distance between the probe and NPs [41-45]. In some cases, there's a positive deviation from a linear Stern-Volmer relation for example in singlet to triplet excitations, formation of charge transfer complexes both at ground and excited states, combined effect of both static and dynamic quenching. In general, three types of quenching processes can occur: (a) static quenching, (b) dynamic quenching, and (c) electron / energy transfer. Adsorption of the probe molecule on the surface of the metallic nanoparticles resulting in a decrease in the emission intensity is a well- known static quenching mechanism. Collision of excited fluorophore with a quencher during their excited state lifetime causes a reduction of emission intensity giving the known dynamic quenching. Nonradiative energy / electron transfer between the probe molecule and NPs is also a route of fluorescence quenching [46-48]. To investigate the interaction of metallic nanoparticles with PPPBB molecule, we measure the emission spectra of PPPBB in absence and presence of different concentrations of AgNPs in methanol and ethylene glycol, respectively to investigate the effect of medium viscosity on the fluorescence quenching rate constants.

As shown in Fig. (3 a-d), the fluorescence intensity of PPPBB decreases with increasing the concentration of metallic AgNPs and AuNPs without changes in the spectral patterns indicating the absence of 
chemical interaction in excited state between metallic nanoparticles and PPPBB. No such quenching of PPPBB was observed in the presence of low concentrations of capping agent indicating that the role of metallic nanoparticles in quenching.

To determine the quenching rate constants, we apply Stern-Volmer relationship (1) in the form:

$$
\frac{I_{o}}{I}=1+K_{S V}[N P]
$$

1

Where $\mathrm{I}_{\mathrm{o}}$ and $\mathrm{I}$ are the fluorescence intensities of PPPBB in the absence and presence of the quencher respectively, $K_{\mathrm{sv}}$ is the Stern Volmer quenching constant $\left(K_{\mathrm{sv}}=k_{q} \tau_{f}\right)$ where $k_{q}$ is the second order quenching rate constant, $\tau$ is the excited state lifetime of PPPBB (measured as $2.17 \mathrm{~ns}$ in methanol), and $\left[N P_{S}\right]$ is the nanoparticle quencher concentration. The linear plots of fluorescence quenching of PPPBB by metallic nanoparticles (AgNPs and AuNPs) are shown in Fig. (4a-b).

As shown in Table 1, the quenching rate constants are much higher than the diffusion rates constants in $\mathrm{MeOH}\left(\mathrm{k}_{\mathrm{d}}=1.1 \times 10^{10} \mathrm{M}^{-1} \mathrm{~s}^{-1}\right)$ or EG $\left(\mathrm{k}_{\mathrm{d}}=3.8 \times 10^{8} \mathrm{M}^{-1} \mathrm{~s}^{-1}\right)$ [49]. This indicates the absence of diffusioncontrolled dynamic quenching. In case of AuNPs, the quenching rate constant $k_{q}$ in EG is more than one order higher than the value in methanol. This is attributed to the role of micro viscosity in imposing a cage effect with concomitant enhancement of static quenching $[50,51]$. On the other hand, the quenching rate constant $\mathrm{k}_{\mathrm{q}}$ in case of AgNPs is more than three orders of magnitudes higher than that for AuNPs in $\mathrm{MeOH}$ and is more than two orders of magnitudes higher than that for AuNPs in EG. This is due to the remarkably large overlap between PPPBB emission and AgNPs plasmonic absorption compared with AuNPs as shown in Figure (5). This leads to a stronger dipole-dipole interaction between excited state of PPPBB and the surface plasmon resonance (SPR) absorption band of AgNPs compared with AuNPs. Due to the overlap between emission spectrum of PPPBB and Plasmon absorption band of nanoparticles, radiative energy transfer is also expected.

The remarkably high fluorescence quenching rate constant values are attributed to the so- called hyper- or super- fluorescence quenching [52]. In general, super-quenching of fluorescence by metallic nanoparticles occurs due to (1) large absorption coefficient of surface plasmon resonance (SPR) absorption band of metallic nanoparticles (2) due to spherical like shaped of AgNPs and AuNPs whereby energy transfer occurs at any orientation of donor relative to nonmetal surface and (3) overlap between emission of donor and SPR absorption band.

To calculate the volume of quenching sphere radius of PPPBB $\left(\mathrm{V}\right.$ in $\left.\mathrm{cm}^{3}\right)$ and the quenching sphere radius ( $r$ in $\mathrm{nm}$ ) we apply the well-known Perrin model relationship [53-55] according to equations ( 2 and 3) 


$$
\ln \frac{I_{o}}{I}=V N_{o}[Q]
$$

2

$\mathrm{V}=4 / 3 \pi r^{3}(3)$

Where $I_{O}$ and $I$ are the fluorescence intensities of PPPBB in the absence and presence of nanoparticles, $V$ is the volume of the quenching sphere in $\mathrm{cm}^{3}, N_{o}$ is the Avogadro's number, [Q] the concentration of the quencher [NP] in mol $d^{-3}, \mathrm{r}$ is the quenching sphere radius in $\mathrm{nm}$. From the plot of $\mathrm{In} \mathrm{I}_{\mathrm{o}} / \mathrm{I}$ versus [NP] we obtained a linear correlation as shown in Fig. (6a-b) with slopes equal $V N_{0}$. The calculated $V$ and $r$ values are listed in Table (1). The radius of PPPBB was determined from X-ray measurements as $R_{d}=$ $0.53 \mathrm{~nm}$, the sum of molecular radii $\mathrm{R}=\mathrm{R}_{\mathrm{d}}+\mathrm{R}_{\mathrm{q}}$, where $\mathrm{R}_{\mathrm{q}}=51 \mathrm{~nm}$ for AgNPs and $17.33 \mathrm{~nm}$ for AuNPs. As shown in Table 1, the radius of active sphere volume was found to be larger than $\mathrm{R}$ indicating that the non-radiative and radiative energy transfer processes are responsible of quenching of fluorescence of PPPBB due to a significant overlap between emission spectrum of PPPBB and Plasmon surface of metallic nanoparticles which enhances the dipolar interaction between excited state of PPPBB and (SPR) nanoparticles.

Table (1) Super-quenching photophysical parameters from Stern-Volmer plots ( $K_{S v}$ values) and from Perrin model (quenching sphere volume $\mathbf{V}$, and radius $\mathbf{r}$ )

\begin{tabular}{|c|c|c|c|c|c|c|c|c|}
\hline \multirow[t]{3}{*}{ Solvent } & \multicolumn{4}{|c|}{$\begin{array}{l}\text { Stern Volmer } \\
\text { parameters }\end{array}$} & \multicolumn{4}{|c|}{$\begin{array}{l}\text { Perrin model } \\
\text { parameters }\end{array}$} \\
\hline & \multicolumn{2}{|l|}{ AgNPs } & \multicolumn{2}{|l|}{ AuNPs } & \multicolumn{2}{|l|}{ AgNPs } & \multicolumn{2}{|l|}{ AuNPs } \\
\hline & $\begin{array}{l}\mathrm{K}_{\mathrm{SV}}\left(\mathrm{M}^{-}\right. \\
\left.{ }^{1}\right)\end{array}$ & $\begin{array}{l}k_{q}\left(M^{-}\right. \\
\left.{ }^{1} s^{-1}\right)\end{array}$ & $\begin{array}{l}\mathrm{K}_{\mathrm{SV}}\left(\mathrm{M}^{-}\right. \\
\left.{ }^{1}\right)\end{array}$ & $\begin{array}{l}k_{q}\left(M^{-}\right. \\
\left.{ }^{1} s^{-1}\right)\end{array}$ & $V\left(\mathrm{~cm}^{3}\right)$ & $\begin{array}{l}r \\
(n m)\end{array}$ & $V\left(\mathrm{~cm}^{3}\right)$ & $\begin{array}{l}r \\
(n m)\end{array}$ \\
\hline $\mathrm{MeOH}$ & $\begin{array}{l}1.4 \times \\
10^{10}\end{array}$ & $\begin{array}{l}6.45 \times \\
10^{20}\end{array}$ & $\begin{array}{l}2.69 \times \\
10^{8}\end{array}$ & $\begin{array}{l}1.24 \times \\
10^{17}\end{array}$ & $\begin{array}{l}1.73 \times \\
10^{-14}\end{array}$ & 160 & $\begin{array}{l}3.84 \times \\
10^{-16}\end{array}$ & 41 \\
\hline EG & $\begin{array}{l}1.2 \times \\
10^{10}\end{array}$ & $\begin{array}{l}5.53 \times \\
10^{20}\end{array}$ & $\begin{array}{l}6.18 \times \\
10^{9}\end{array}$ & $\begin{array}{l}2.85 \times \\
10^{18}\end{array}$ & $\begin{array}{l}1.75 \times \\
10^{-14}\end{array}$ & 161 & $\begin{array}{l}2.64 \times \\
10^{-15}\end{array}$ & 85 \\
\hline
\end{tabular}

\section{Conclusion}

Super fluorescence quenching of 1-(E)-styryl-2-(4-(2-(E)-styrylphenoxy)butoxy)benzene (PPPBB) by AgNPs and AuNPs was studied in methanol and ethylene glycol solvents. The fluorescence quenching data reveal that non radiative and radiative energy transfer play a major role in the fluorescence quenching mechanism. The Stern -Volmer quenching rate constants $\left(\mathrm{K}_{\mathrm{sv}}\right)$ as well as the quenching rate constants 
$\left(\mathrm{k}_{\mathrm{q}}\right)$ were calculated. Two solvents of different viscosities namely ethylene glycol and methanol were used to assess the role of cage effect in enhancing static quenching. The quenching sphere radius $r$ values were calculated for AgNPs and AuNPs quenchers. The radii of active sphere volume were found to be larger than the respective nanoparticles radii indicating contribution of both non-radiative and radiative energy transfer processes in the fluorescence quenching of PPPBB* by metallic nanoparticles due to a significant overlap between SPR of metal nanoparticles and PPPBB*

\section{Declarations}

- Funding (Transformative Agreement plus fully OA agreement with Egypt)

- Conflicts of Interest: The authors declare that they have no conflict of interest.

- Ethical Approval: This article does not contain any studies with human or animal subjects.

- Consent to participate (All authors accept participation)

- Consent for publication (All authors accept publication)

- Availability of data and material/ Data availability (NA)

- Code availability (NA)

- Authors' contributions (Rasha M. Bayoumy: Methodology and writing original draft, Shakir T. AbdelHalim: investigation and supervision, Samy A. El-Daly: Conceptualization, supervision and investigation, Ahmed A. Abo-Alhasan: contributed to discussion and copy editing, El-Zeiny M. Ebeid: Review, editing and supervision)

\section{References}

[1] Thomas KG, Kamat PV (2003) Chromophore-functionalized gold nanoparticles. Accounts of chemical research $36: 888-898$.

[2] Kushlyk M, Tsiumra V, Zhydachevsky Y, Haiduchok V, Syvorotka I, Sugak D, Pieniążek A, Aleszkiewicz AM, Suchocki A (2021) Preparation and properties of Ag plasmonic structures on garnet substrates. Applied Nanoscience 1-18.

[3] Lakowicz JR, Fu Y (2009) Modification of single molecule fluorescence near metallic nanostructures.

\section{Laser \& photonics reviews 3 : 221-232.}

[4] Wenger J (2019) Fluorescence spectroscopy enhancement on photonic nanoantennas. Plasmonics in Chemistry and Biology, (Chapter 6) Eds: Nordin Felidj and Marc Lamy de la Chapelle, Pan Stanford editions: arXiv:1709.06749\{Physics. Chem.Ph]

[5] Zhang J, Matveeva E, Gryczynski I, Leonenko Z, Lakowicz JR (2005) Metal-enhanced fluoroimmunoassay on a silver film by vapor deposition. J Phys Chem B 109 : 7969-7975. 
[6] Zhang J, Malicka J, Gryczynski I, Lakowicz JR (20005) Surface-enhanced fluorescence of fluoresceinlabeled oligonucleotides capped on silver nanoparticles. J Phys Chem B 109 : 7643-7648.

[7] Padma M, Govindh B, Rao BV (2014) Synthesis \& characterization of fluorescent silver nanoparticles stabilized by Tinospora Cordifolia leaf extract a green procedure. Journal of Engineering Research and Applications 4 : 100-107.

[8] Corrigan T, Guo S,. Phaneuf R, Szmacinski H (2005) Enhanced fluorescence from periodic arrays of silver nanoparticles. J Fluoresc 15 :777-784.

[9] Vladimir NM, Maria AK, Olga VD, Victor MR, Vladimir AK(2020), fluorescence superquenching of SYBR lin crowded DNA gold nanoparticles. J Lumin 219:116898

[10] Haes AJ, Stuart DA, Nie S, R.P. Van Duyne RP (2004) Using solution-phase nanoparticles, surfaceconfined nanoparticle arrays and single nanoparticles as biological sensing platforms. $J$ fluoresc 14 : 355-367.

[11] Chamuah N, Vaidya GP, Joseph AM, Nath P (2017) Diagonally aligned squared metal nano-pillar with increased hotspot density as a highly reproducible SERS substrate. Plasmonics 12 : 1353-1358.

[12] Kotiaho A, Lahtinen R, Latvala RH, A. Efımov A, Tkachenko NV, Lemmetyinen H(2009), Effect of gold nanoparticles on intramolecular exciplex emission in organized porphyrin-fullerene dyad films. Chem

Phys Lett 471 : 269-275.

[13] Pramanik S, Bhattacharya SC, Imae T (2007) Fluorescence quenching of 3, 7-diamino-2, 8-dimethyl-5phenyl phenazinium chloride by AgCl and Ag nanoparticles. J Lumin 126: 155-159.

[14] Porcal GV, Chesta CA, Biasutti MA, Bertolotti SG, Prevital CM (2012) Quenching of the triplet state of safranine $O$ by aliphatic amines in AOT reverse micelles studied by transient absorption spectroscopy. $J$ Photochem\& Photobiol Sciences 11 : 302-308.

[15] Landes CF, Braun M, El-Sayed MA (2001), On the nanoparticle to molecular size transition: fluorescence quenching studies, J Phys Chem B 105: 10554-10558

[16] Saleh SM, Ali R, O.S. Wolfbeis OS (2011), Quenching of the luminescence of upconverting luminescent nanoparticles by heavy metal ions. European Journal of Chemistry $17: 14611-14617$.

[17] Lee IYS, Suzuki H (2008), Quenching dynamics promoted by silver nanoparticles. J Photochem and Photobiol A: Chem195: 254-260.

[18] Saad SM, Abdullah J, Abd Rashid S, Fen YM, Salam F, Yih LH (2019), A fluorescence quenching based gene assay for Escherichia coli 0157: H7 using graphene quantum dots and gold nanoparticles.

Microchimica Acta 186 : 1-10. 
[19] Lakowicz JR (2006) Principles of fluorescence spectroscopy, $3^{\text {rd }}$ edn. Springer, New york, Chapter 8 [20] Filmon F, Delaude K, Demonceau L, Noels AF (2004). Coord Chem Revs 248 : 121-124.

[21] Likhtenshtein G, Papper V,. Pines D, Pines E (1997), Photochemical and photophysical characterization of 4, 4ל-substituted stilbenes linear free energy. Recent research development in photochem and photobiol. 205-250.

[22] Papper V, Likhtenshtein, GI (2001), Substituted stilbenes: a new view on well-known systems: "New applications in chemistry and biophysics", J Photochem and Photobiol A: Chem 140 : 39-52.

[23] Smirnov AN, Odintsova OV,. Solovyeva EV (2019), in: PHOTOPTICS, New Photonic Materials based on Ag Nanoparticles Modified with Stilbene Dyes and Its Peculiar Behavior Studied with SERS.

Proceeding of the $7^{\text {th }}$ international conference on photonics, optics and laser technology, Prague, Czch Republic: 263-267.

[24] De Filippis D, Ammazzalorso A, Fantacuzzi M, Giampietro L, Maccallini C, Amoroso R(2017), Anticancer activity of stilbene-based derivatives. Chem Med Chem 12: 558-570.

[25] Böhn A, Adam M, Mauermann H, Stein S, Müllen K (1992), Solid-State Photoreactivity of orthodistyrylaromatic compounds. Tetrahedron Lett 33: 2795-2798.

[26] Lee P, Meisel D (1982), Adsorption and surface-enhanced Raman of dyes on silver and gold sols. $J$ Phys Chem 86 (1982): 3391-3395.

[27] Ullah S, Baloch MK, Nawaz M, Rehman ZU, Rehman W, Uddin I, Khan QU (2020), Investigation of stability and rheological properties of silver nanoparticles stabilized by polyethylene glycol. Journal of materials science-materials in electronics 31(1):10470-10477

[28] Grabar KC, Freeman RG, Hommer MB,.Natan MJ(1995), Preparation and characterization of Au colloid monolayers., Analyt chem 67 : 735-743.

[29] Yuan H, Ji W. Chu S, Liu Q, Guang J, Sun G, Zhang Y, Han X, Masson JF, Peng W(2020), Au nanoparticles as label-free competitive reporters for sensitivity enhanced fiber-optic SPR heparin sensor. Biosensors and Bioelectronics 154: 112039.

[30] Frens G (1973), Controlled nucleation for the regulation of the particle size in monodisperse gold suspensions. Nature physical science $241: 20-22$.

[31] Alhag SK, Al-Mekhlafi FA, Abutaha N, Abd Al Galil FM, Wadaan MA(2021), Larvicidal potential of gold and silver nanoparticles synthesized using Acalypha fruticosa leaf extracts against Culex pipiens (Culicidae: Diptera). J of Asia Pacific Entomology 24(1)184-189 
[32] Kuyper AC (1933), “The oxidation of citric acid”. J Am Chem Soc 55 : 1722-1727.

[33] Polte J, Erler R, Thunemann AF, Sokolov S, Ahner TT, Rademann K, Emmerling F, Kraehnert R(2010), Nucleation and growth of gold nanoparticles studied via in situ small angle X-ray scattering at millisecond time resolution. ACS nano 4 :1076-1082.

[34] Tofighi G, Lichtenberg H, Pesek J, Sheppard TL, Wang W, Schöttner L, Rinke G, Dittmeyer R, Grunwaldt JD, (2017),Continuous microfluidic synthesis of colloidal ultrasmall gold nanoparticles: in situ study of the early reaction stages and application for catalysis., Reaction Chemistry \& Engineering 2 : 876-884.

[35] Al-Soliemy AM, Osman OI, Hussein MA, Asiri AM, El-Daly SA(2016), Fluorescence, Photophysical Behaviour and DFT Investigation of E, E-2, 5-bis [2-(3-pyridyl) ethenyl] pyrazine (BPEP)., J fluoresc 6 : 1199-1209.

[36] Njoki PN, Solomon LV, Wu W, Alam R, Maye MM (2011), Attenuating surface plasmon resonance via core/alloy architectures. Chemical Communications 47: 10079-10081.

[37] Deng W, Goldys EM (2012), Plasmonic approach to enhanced fluorescence for applications in biotechnology and the life sciences. Langmuir 28: 10152-10163.

[38] La Deda M, Candreva A, Di Maio G (2020), A Quick One-Step Synthesis of Luminescent Gold Nanospheres. Soft Matter 16: 10865-10868

[39] Fu Y, Zhang J, Lakowicz JR(2007), Plasmonic enhancement of single-molecule fluorescence near a silver nanoparticle .J fluoresc 17: 811-816.

[40] Ugwuoke LC, Mančal T, Krüger TP (2020), Plasmonic quantum yield enhancement of a single molecule near a nanoegg. J Appl Phys 127: 203103.

[41] Kalele S, Deshpande AC, Singh SB, Kulkarni S (2008), Tuning luminescence intensity of R6G dye using silver nanoparticles. Bulletin of Materials Science 31: 541-544.

[42] Jelvani S (2019), Effect of Ag nanoparticles on the amplifying parameters of a dye laser amplifier. Optik 199: 163330.

[43] Rainò G, Stöferle T, Park C, Kim HC, Topuria T, Rice PM I, Chin J, Miller RD, Mahrt RF (2011), Plasmonic nanohybrid with ultrasmall Ag nanoparticles and fluorescent dyes. ACS nano 5: 3536-3541.

[44] Xu J, Zhou S, Tu D, Zheng W, Huang P, Li R, Chen Z, Huang M, Chen X (2016) Sub-5 nm lanthanidedoped lutetium oxyfluoride nanoprobes for ultrasensitive detection of prostate specific antigen. Chemical science 7: 2572-2578.

[45] Chung H, Leung PT, Tsai D (2013), Molecular fluorescence in the vicinity of a charged metallic nanoparticle. Optics express 21: 26483-26492. 
[46] Maxwell DJ, Taylor JR, Nie S (2002), Self-assembled nanoparticle probes for recognition and detection of biomolecules. J Am Chem Soc 124: 9606-9612.

[47] Fan GC, Zhao H, Ma L, Lu Y,. Luo X (2020), A distance-triggered signaling on-off mechanism by plasmonic Au nanoparticles: toward advanced photocathodic DNA bioanalysis. Chemical

Communications 56: 1345-1348.

[48] Pannipara M, Asiri AM, Alamry KA, Arshad MN, El-Daly SA(2015), Synthesis, spectral behaviour and photophysics of donor-acceptor kind of chalcones: excited state intramolecular charge transfer and fluorescence quenching studies. Spectrochimica Acta Part A: Molecular and Biomolecular Spectroscopy 136 : 1893-1902.

[49] Calvert, J. G. and Pitts, J. N., Photochemistry, John Wiley \& Sons, New York, London, (1966) p. 627; Ebeid, E. M. and AlHazmy, S. M. Photophysical and Laser-Based Techniques in Chemistry, Biology and Medicine, BookSurge Publisher (2006) USA p. 43.

[50] El-Daly SA, Rahman MM, Alamry KA,. Asiri AM (2014), Fluorescence quenching of N,N-bis(2,5-di-tertbutylphenyl)-3,4 :9,10-perylenebis(dicarboximide) by silver nanoparticles . J lumin148:303-306; El-Daly SA, Rahman MM, Alamry KA,. Asiri AM (2014), Fluorescence quenching of N,N-bis(2,5-di-tertbutylphenyl)-3,4 :9,10-perylenebis(dicarboximide) by silver nanoparticles . J Iumin148:303-306

[51] El-Daly SA, Salem IA, Hussein MA, Asiri AM (2015),Fluorescence quenching of N,N-bis(2,6dimethylphenyl)-3,4:9,10-perylenetetracarboxylic diimide laser dye by colloidal silver nanoparticles. $J$.

\section{Fluoresc 25:379-385}

[52] Morozov NV, Kolyvanova AM, Dementeva OV, Rudoy VM, Kuzmin VA (2020), Fluorescence superquenching of SYBR Green I in crowded DNA by gold nanoparticles. Lumin 219:116898

[52] Brown SB, "Introduction to spectroscopy for biochemists", Academic Press, (1980).

[53] Bigham SR, Coffer JL (1992), Deactivation of Q-cadmium sulfide photoluminescence through polynucleotide surface binding., J Phys Chem 96 : 10581-10584.

[54] El-Daly SA, Rahman MM, Alamry KA, A.M.Asiri AM (2015), Fluorescence quenching of perylene DBPI dye by colloidal low-dimensional gold nanoparticles. J Flurosc 25 : 973-978.

\section{Figures}




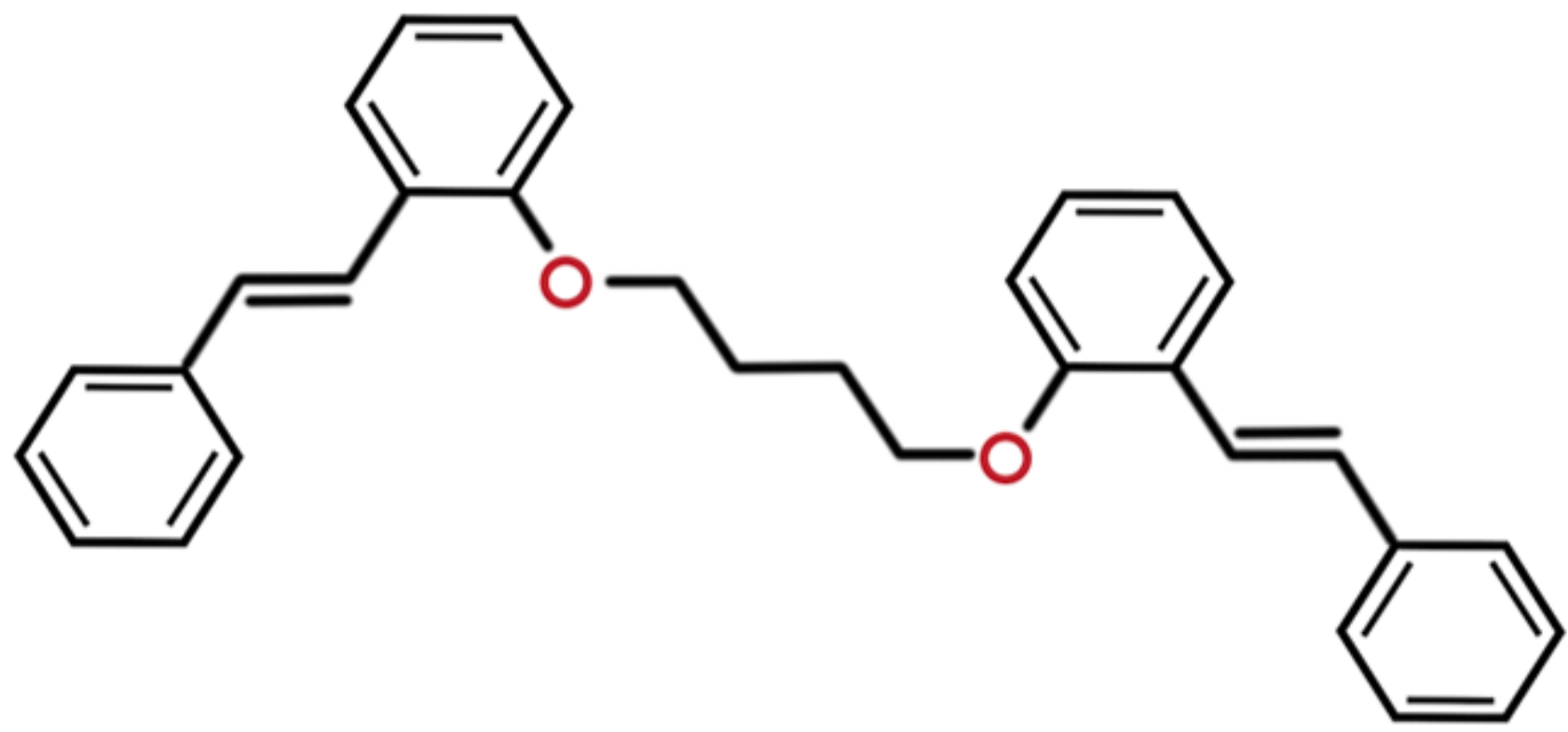

Figure 1

1-((E)-2-phenylethenyl)-2-(4-(2-((E)-2-phenylethenyl) phenoxy) butoxy) benzene (PPPBB) 

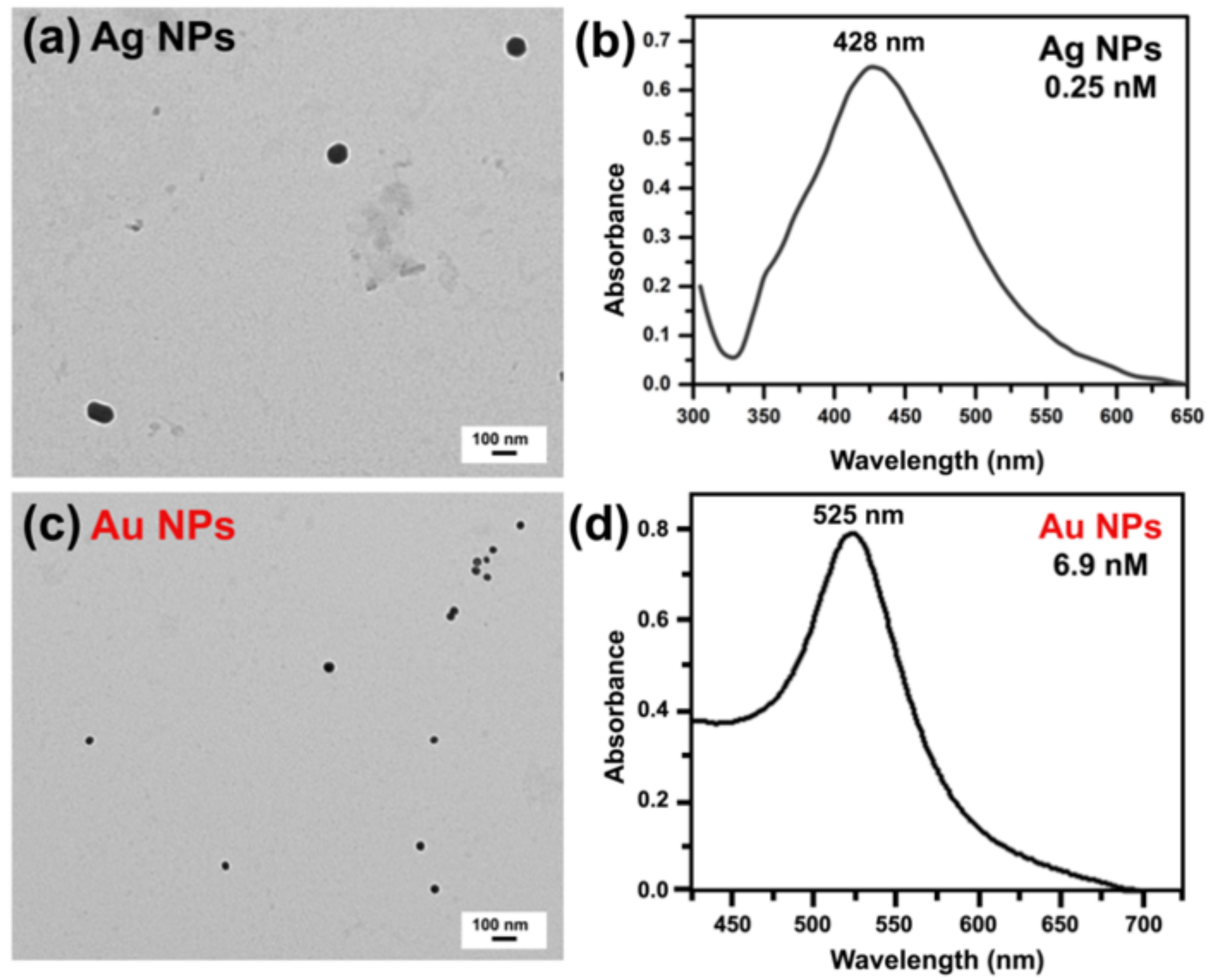

Figure 2

(a) TEM images of the as prepared AgNPs, (b) absorption spectrum of $0.25 \mathrm{n} \mathrm{M} \mathrm{AgNPs} \mathrm{aqueous} \mathrm{solution,}$ (c) AuNPs TEM image and (d) Electronic absorption spectrum of $6.9 \mathrm{n}$ M AuNPs aqueous solution. 
(a)

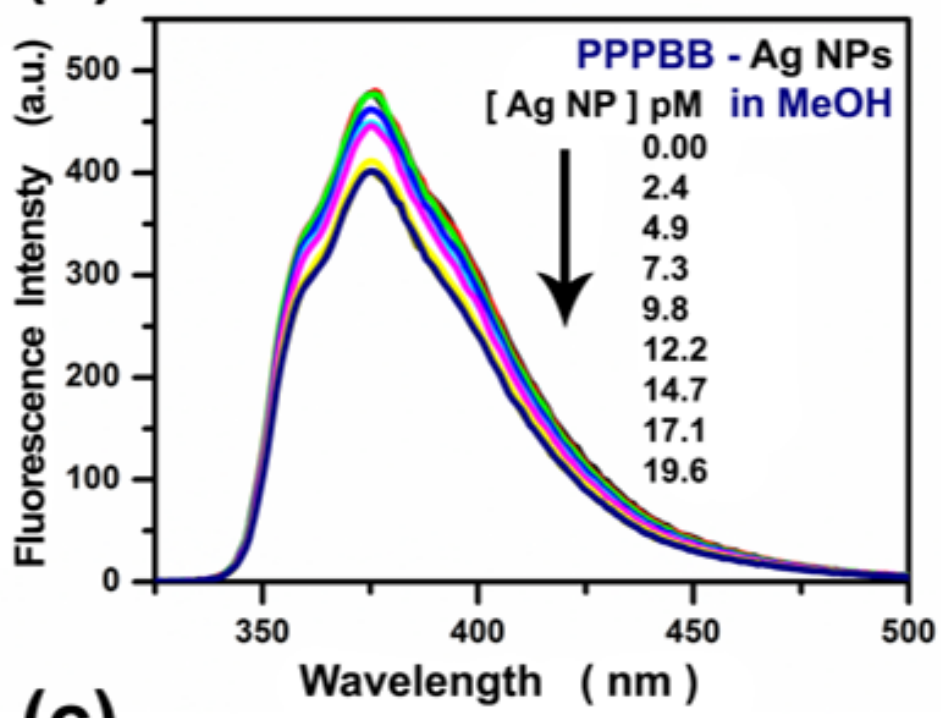

(c)

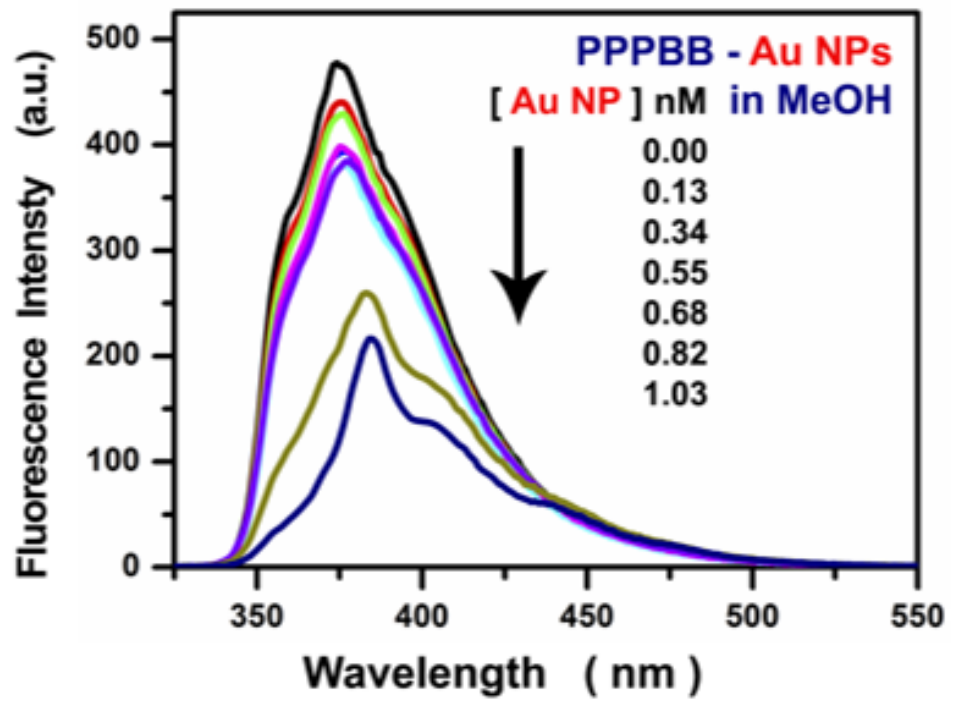

(b)

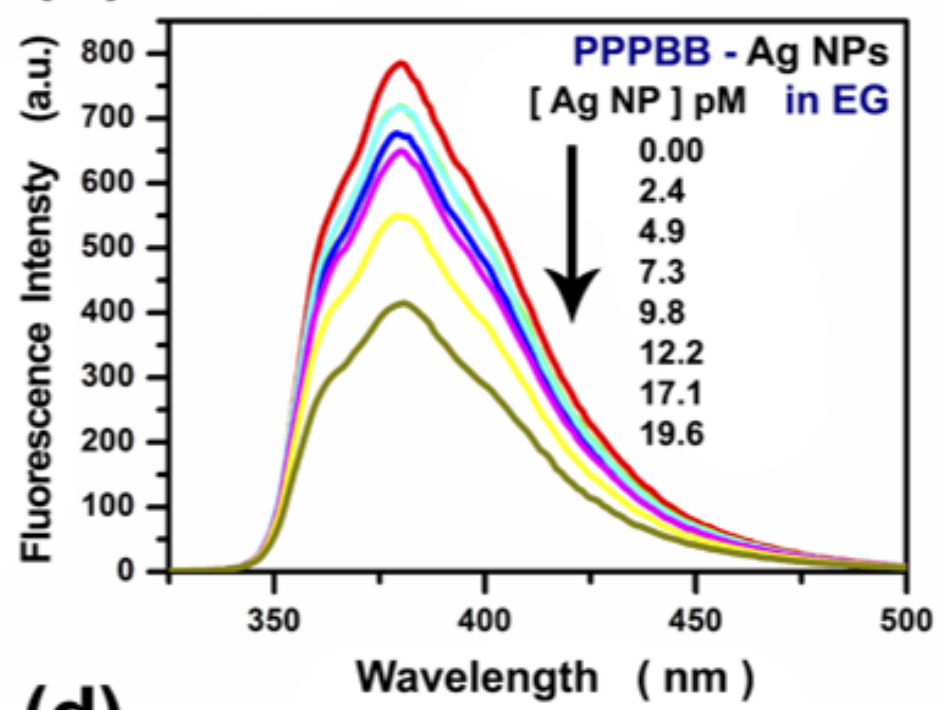

(d)

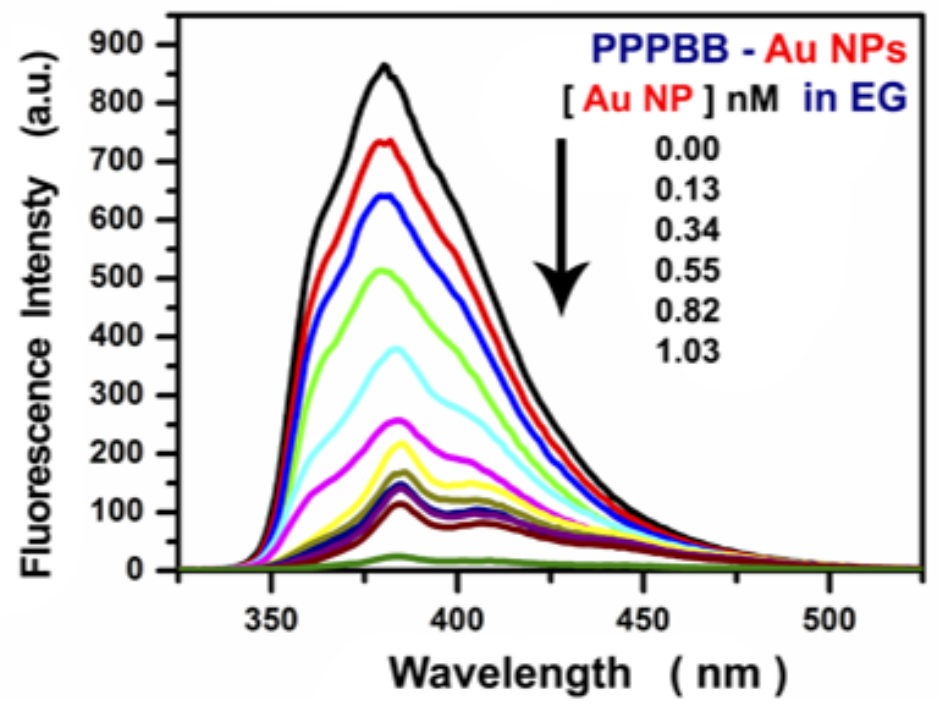

Figure 3

( $(a$ and $\mathbf{b}$ ) Emission spectra of $\mathrm{M}$ solutions of PPPBB in MeOH and in EG in the presence of different concentrations of AgNPs. ( $c$ and d) Emission spectra of $\mathrm{M}$ solution PPPBB in MeOH and EG at different concentrations of AuNPs. $\left(\lambda_{\mathrm{ex}}=313 \mathrm{~nm}\right)$. 

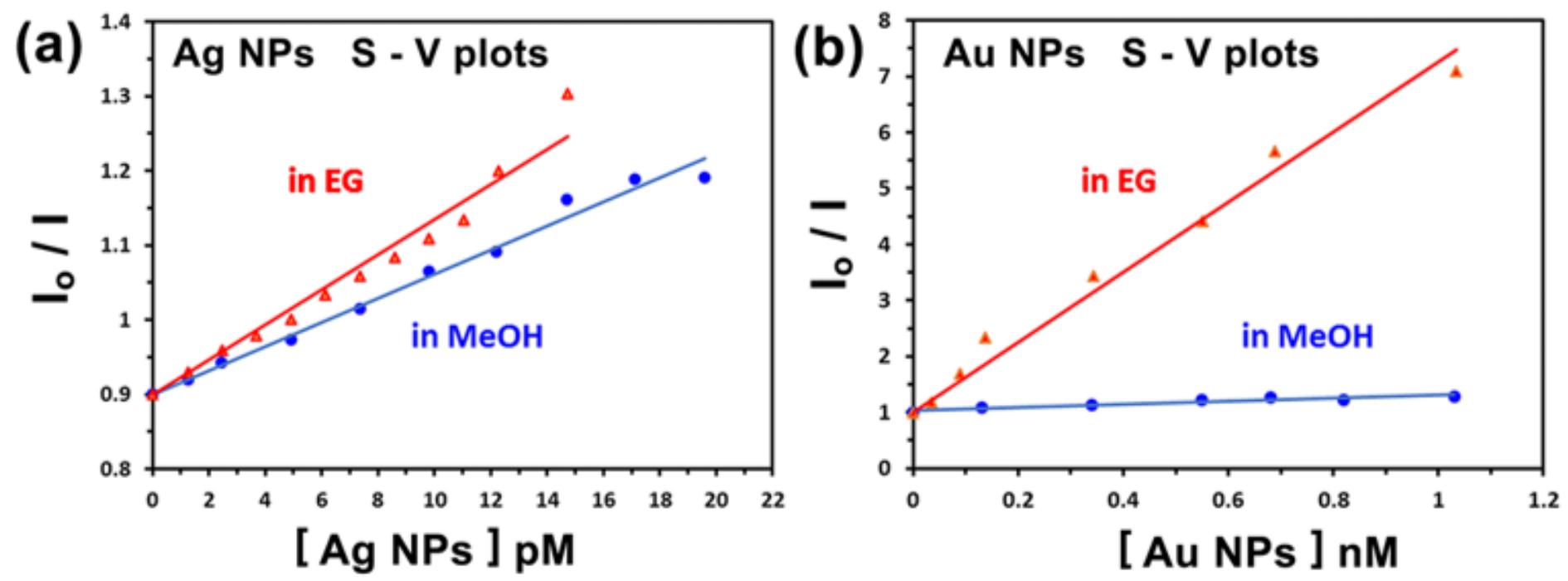

Figure 4

Stern-Volmer plots of super- fluorescence quenching of $\mathbf{M}$ solution PPPBB (a) by Ag NPs in $\mathrm{MeOH}$, and EG and (b) by AuNPs in MeOH and EG. 


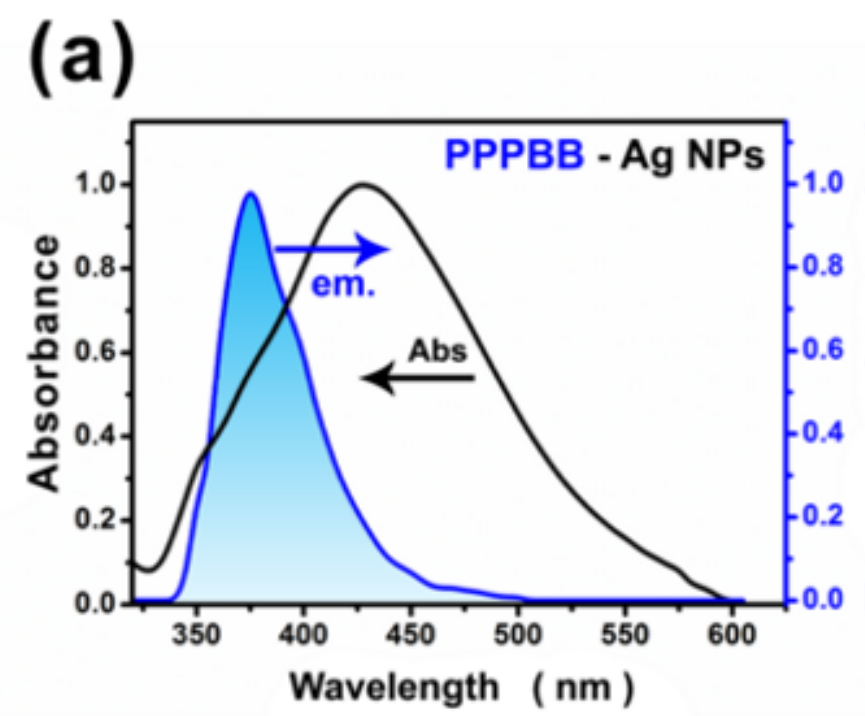

\section{(c)}

(b)
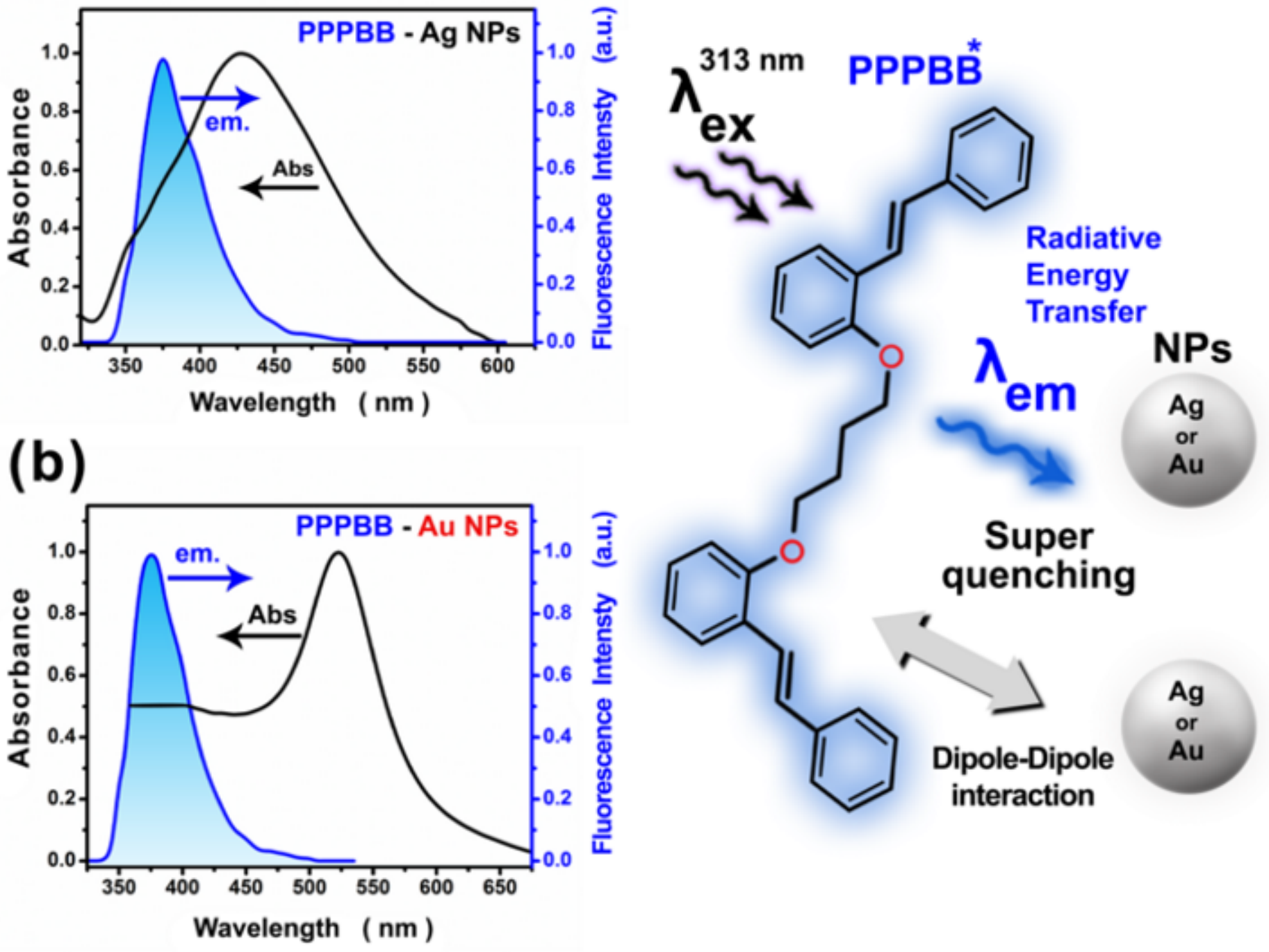

Figure 5

(a) Overlap between the fluorescence emission spectrum of PPPBB and electronic absorption spectra of nM AgNPs; (b) Electronic emission spectrum of PPPBB and electronic absorption spectra of nM AuNPs and (c) Schematic illustration for the super-quenching proposed mechanism of PPPBB by AgNPs or AuNPs. 

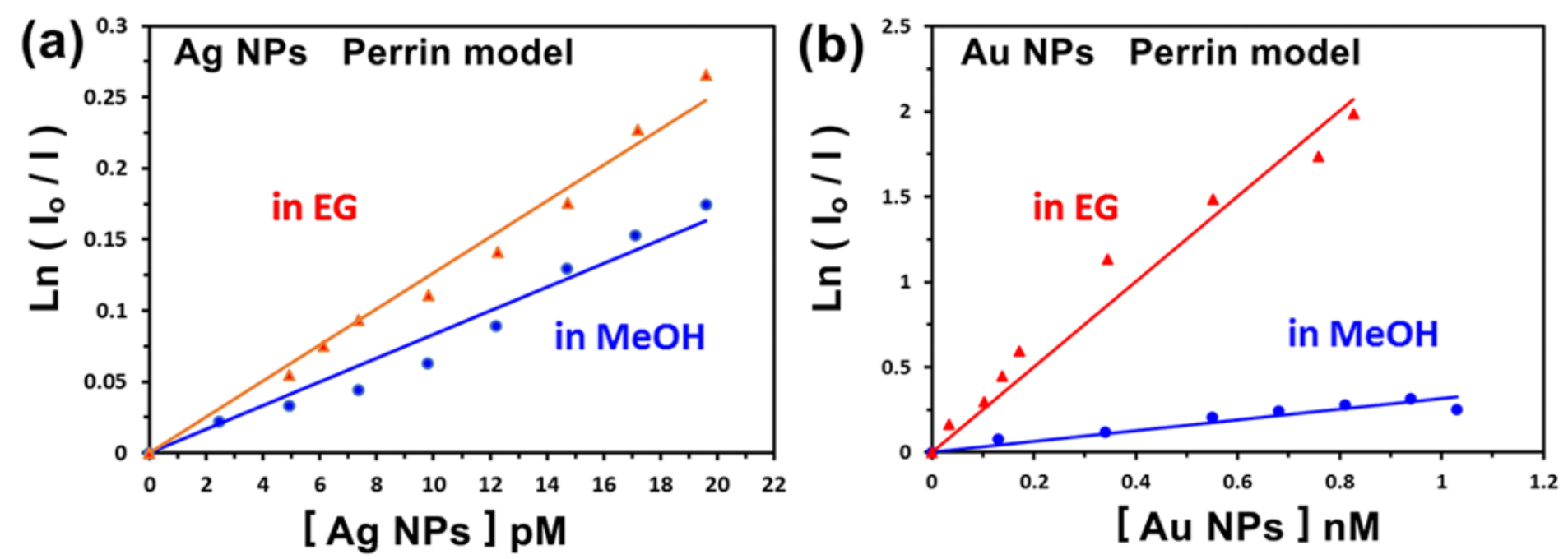

Figure 6

Perrin model for fluorescence super-quenching of $\mathrm{M}$ solution PPPBB by (a) AgNPs in $\mathrm{MeOH}$, and EG and (b) AuNPs in $\mathrm{MeOH}$ and EG. 